\title{
The effect of spinal osteotomies on spinal cord tension and dural buckling: a cadaveric study
}

\author{
${ }^{*}$ Mina G. Safain, MD, ${ }^{1,2}$ Shane M. Burke, BS,, ${ }^{1,2}$ Ron I. Riesenburger, MD, ${ }^{1,2}$ \\ Vasilios Zerris, MD, MPH, ${ }^{3}$ and Steven W. Hwang, MD ${ }^{1,2}$ \\ 1Department of Neurosurgery, Tufts Medical Center; '2Department of Neurosurgery, Tufts University School of Medicine, Boston, \\ Massachusetts; and 'University of Cyprus, Nicosia, Cyprus
}

\begin{abstract}
OBJECT The standard surgical release of a tethered cord may result in recurrent scar formation and occasionally be associated with retethering. The application of spinal shortening procedures to this challenging problem potentially can reduce tension on the retethered spinal cord while minimizing the difficulties inherent in traditional lumbosacral detethering revision. Although spinal shortening procedures have proven clinical benefit in patients with a recurrent tethered cord, it is unclear how much shortening is required to achieve adequate reduction in spinal cord tension or what impact these osteotomies have on dural buckling.

METHODS The authors calculated mean values from 4 human cadavers to evaluate the effect of 3 different spinal shortening procedures-Smith-Petersen osteotomy (SPO), pedicle subtraction osteotomy (PSO), and vertebral column resection (VCR) - on spinal cord tension and dural buckling. Three cadavers were dedicated to the measurement of spinal cord tension, and 3 other cadavers were devoted to myelography to measure dural buckling parameters.

RESULTS The SPO was associated with a maximal decrease in spinal cord tension of $16.1 \%$ from baseline and no dural buckling with any degree of closure. The PSO led to a mean maximal decrease in spinal cord tension of $63.1 \%$ from baseline at $12 \mathrm{~mm}$ of closure and demonstrated a direct linear relationship between dural buckling and increasing osteotomy closure. Finally, VCR closure correlated with a mean maximal decrease in spinal cord tension of $87.2 \%$ from baseline at $10 \mathrm{~mm}$ of closure and also showed a direct linear relationship between dural buckling and increases in osteotomy closure.
\end{abstract}

CONCLUSIONS In this cadaveric experiment, the SPO did not lead to appreciable tension reduction, while a substantial response was seen with both the PSO and VCR. The rate of tension reduction may be steeper for the VCR than the PSO. Adequate tension relief while minimizing dural buckling may be optimal with 12-16 mm of posterior osteotomy closure based on this cadaveric experiment.

http://thejns.org/doi/abs/10.3171/2014.11.SPINE14877

KEY WORDS tension; dural buckling; tethered cord syndrome; Smith-Petersen osteotomy; pedicle subtraction osteotomy; vertebral column resection; technique

$\mathrm{T}$ EeTHERED cord syndrome is a clinical condition characterized by traction on nerve roots and the spinal cord that can cause pain and neurological dysfunction. Patients often present with some form of neural tube defect and can suffer from symptoms such as back or leg pain, gait difficulties, lower-extremity weakness, sensory deficits, and bowel/bladder dysfunction. Initial treatment of tethered cord syndrome involves detethering, which consists of the surgical release of abnormal attachments between the neural elements and adjacent structures, thereby releasing undue tension on the spinal cord.

Detethering is a well-established treatment option for tethered cord syndrome. ${ }^{6,20,21}$ Unfortunately, scar tissue formation after detethering operations often causes multiple instances of retethering of neural elements and redevelopment of symptoms. Recurrent tethering has been reported to occur in up to $30 \%$ of adult patients, ${ }^{7,12-14}$ and between $10 \%$ and $30 \%$ of children. ${ }^{4,5,22}$ Multiple repeated surgeries

ABBREVIATIONS PSO = pedicle subtraction osteotomy; $\mathrm{SPO}=$ Smith-Petersen osteotomy; VCR = vertebral column resection. SUBMITTED August 25, 2014. ACCEPTED November 4, 2014.

INCLUDE WHEN CITING Published online April 17, 2015; DOI: 10.3171/2014.11.SPINE14877.

DISCLOSURES The authors report no conflict of interest concerning the materials or methods used in this study or the findings specified in this paper. Cadavers were supplied by Depuy-Synthes Companies and NuVasive Inc. for use in educational courses.

* Dr. Safain and Mr. Burke contributed equally to this work. 
on these patients pose a technical challenge, and sequential surgeries are associated with a progressively increasing risk for iatrogenic injury as well as a diminishing benefit. ${ }^{1,23}$

Due to these limitations, new approaches to tethered cord syndrome have been proposed. Spinal shortening osteotomies avoid the problem of retethering by indirectly addressing recurrent lumbosacral scar formation from the thoracolumbar spine through a reduction in the distance tethered. In doing so, these procedures have been theorized to decrease tension at the point of tethering ${ }^{15,19}$ with good outcomes..$^{10,11,15,19,24}$

Although the benefits of shortening procedures in such patients are compelling, the extent of shortening required to achieve symptomatic relief compared with the limit at which iatrogenic injury can occur is not well understood. While tension previously has been investigated in human cadaveric models of tethered cord syndrome, ${ }^{8}$ dural buckling has only been investigated in animal models. ${ }^{1,16,19,25}$ We hypothesized that 2 parameters define the boundaries of this region: tension reduction and dural buckling. The primary aim of this study was to better define the range of tension reduction and dural buckling in a human cadaveric model.

\section{Methods \\ Surgical Technique}

Six human cadavers fixed in formalin were used for 2 independent experiments. In all cadavers, subperiosteal dissections were performed to expose the lamina and facet joints in the lower thoracic spine. Using fluoroscopic guidance, pedicle screws were placed into the bilateral pedicles of T-8, T-9, and T-11 (range in screw size [width by length]: 4.35-5.0 × 40-45 mm). Smith-Petersen osteotomies (SPOs) were performed at T8-9. Pedicle subtraction osteotomies (PSOs) and vertebral column resections (VCRs) were performed at T-10.

The T-10 vertebra was selected as the PSO and VCR site because, in our experience, candidates for these procedures have undergone numerous lumbar surgeries, resulting in complex and extensive scarring. Many of these patients have exaggerated lumbar lordosis that may also increase the difficulty during exposure and the associated wound-healing risk. Therefore, we choose to avoid reoperating in the lumbar region to minimize wound dehiscence and potential CSF leak complications. The SPO only required a facetectomy, thus the lamina of only one and onehalf vertebral levels (T-10 and part of T-9) were removed. No additional decompression was performed immediately above or below the osteotomies for the SPO. A complete laminectomy was performed at the level of the PSO and $\mathrm{VCR}$, along with one-half of the rostral adjacent lamina.

\section{Smith-Petersen Osteotomy}

An SPO was first performed by removing the spinous process of T-8. The inferior articular process of T-8 and superior articular process of T-9 were then removed bilaterally. These facetectomies were extended rostrally to the pedicles of T-8, caudally to the pedicles of T-9, and laterally across the entire facet complex. The ligamentum flavum was then removed.

\section{Pedicle Subtraction Osteotomy}

A PSO was performed by removing the inferior articular processes, lamina, facets, transverse processes, and pedicles of T-10, as well as some of the caudal lamina of T-9. The rib heads of T-10 were also removed and the nerve roots transected, followed by resection of a wedgeshaped portion of the T-10 vertebral body. The posterior height of the wedge was made as tall as possible, whereas only $1 \mathrm{~mm}$ of ventral vertebral body cortex was removed.

\section{Vertebral Column Resection}

After PSO experimentation was completed, the PSO was converted to a VCR by proceeding with a partial vertebrectomy of T-10 and additional removal of the T9-10 disc. The VCR was completed by removing the remaining vertebral column to create parallel surfaces between the remaining $\mathrm{T}-10$ body and $\mathrm{T}-\mathrm{9}$ inferior endplate.

\section{Experiment 1: Evaluation of Spinal Osteotomies on Spinal Cord Tension}

The tension measures were performed on 3 cadavers with intact heads. We used a tension meter (dynamometer) accurate to $0.1 \mathrm{~g}$ within a range of $0.1-225 \mathrm{~g}$ (First Class Pro; US Balance). A laminectomy was performed in the lower lumbar spine and the dura opened in the midline. The filum terminale was anchored to the distal end of the dynamometer with a silk suture tied in a Roman sandal fashion (Fig. 1). A long pedicle screw was placed through the sacrum, and the proximal end of the dynamometer was fixed to it with a locking set screw.

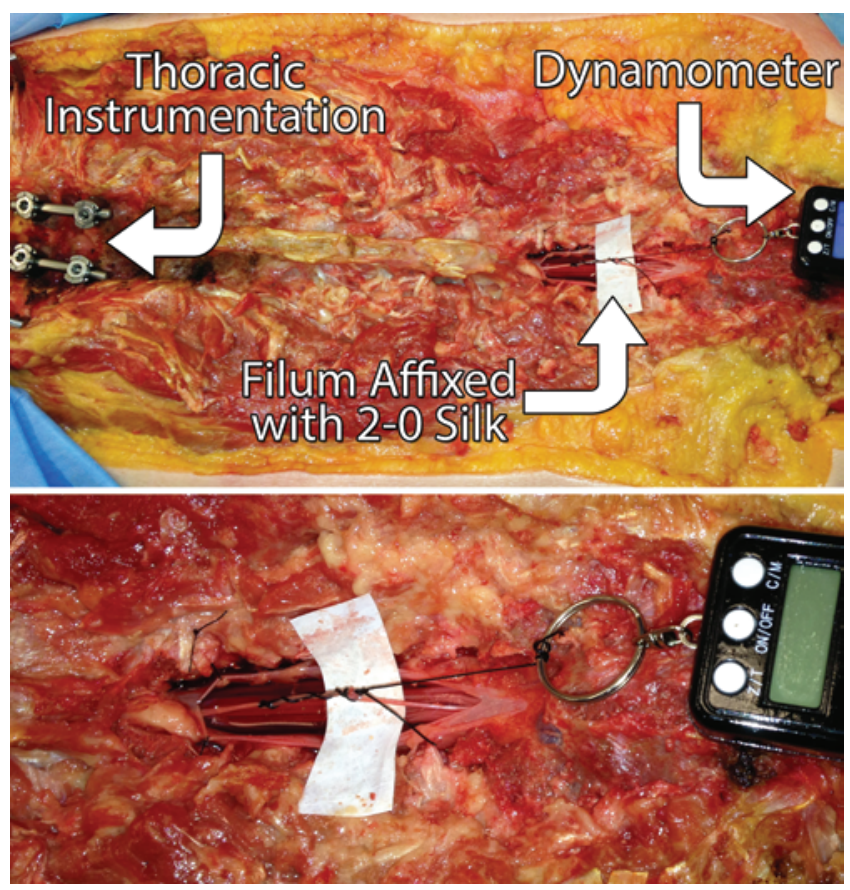

FIG. 1. Photographs of setup for Experiment 1. Upper: Photograph demonstrating thoracic instrumentation at the T8-9 level. The dura is opened in the lumbar spine and affixed to the dynamometer with 2-0 silk. Lower: Magnified view of the photograph demonstrating the filum terminale affixed to the dynamometer with 2-0 silk. Figure is available in color online only. 
Each osteotomy was evaluated with 3 different trials of baseline tension: $10 \mathrm{~g}, 20 \mathrm{~g}$, and $40 \mathrm{~g}$, respectively. All 3 trials were completed for one osteotomy before proceeding to the next. For each tension trial, the filum was stretched until the desired baseline tension was set. The change in tension was measured at each interval of closure until the osteotomy could not be closed any further. The distance closed for each trial was the dorsal measurement between the remaining lamina of the adjacent levels.

The SPO was closed in 2-mm increments to a maximum of $6 \mathrm{~mm}$. Rods were placed across the SPO and tightened to the baseline distance between T-8 and T-9. The PSO was performed, and tension measurements were obtained in 2-mm increments to a maximum of $14 \mathrm{~mm}$ of closure. Finally, a VCR was performed at the same level. The VCR was closed in 2-mm increments to $18 \mathrm{~mm}$.

\section{Experiment 2: Evaluation of Spinal Osteotomies on Dural Buckling}

Dural buckling was evaluated in 3 cadavers. A laminectomy was performed in the lower lumbar spine and in the upper thoracic spine (above and below the planned osteotomy sites). The thecal sac was tied off at these sites and distended with saline. Contrast (Omnipaque [iohexol], 240 $\mathrm{mg} / \mathrm{ml}$; GE Healthcare) was then injected in the expanded thecal sac between the ties. For each osteotomy, baseline lateral radiographs of the T8-11 levels were obtained. Subsequent lateral radiographs were taken at each interval of closure until the osteotomy could not be closed any further.

The SPO was closed in 2-mm increments to a total of $6 \mathrm{~mm}$. Again, rods were placed across the SPO and tightened to the baseline distance between T-8 and T-9. The PSO was performed, and lateral radiographs were obtained every $2 \mathrm{~mm}$ during $14 \mathrm{~mm}$ of closure. Finally, the VCR was performed and closed in 5-mm intervals, since dural buckling was deemed to be consistent during the PSO portion of the experiment.
Three canal measurements were made: anterior dural buckling, canal width, and posterior dural buckling (Fig. 2). All radiographs were uploaded into Adobe Illustrator CS6 (Adobe Systems, Inc.) configured with the SubScribe plugin (Astute Graphics Ltd.). Anterior dural buckling was measured by first drawing a fixed-length reference line between the most anterior part of the dura rostral and caudal to the level of the osteotomy. A line orthogonal to this reference was then drawn to the deepest point of dural indentation. The length of this line was defined as anterior buckling. Canal width was defined as the narrowest distance of the thecal sac at the osteotomy level. Posterior dural buckling was considered the orthogonal distance between the deepest point of dorsal dural indentation and an inferred reference line along the posterior dural margin. The marked-up radiographs were then uploaded into Adobe Photoshop CS6 (Adobe Systems, Inc.) to be measured.

\section{Statistical Analysis}

The mean of the data was calculated from each osteotomy and trial. Given that the shapes of the curves generated by the 20- and 40-g trials approximated each other closely for each osteotomy (Fig. 3A and B), we determined the mean of the results of these 2 trials to simplify the comparison with tension reduction. All tensions were reported as the percent change in tension from baseline. Anterior dural buckling, canal narrowing, and posterior dural buckling were each individually expressed as percentages of the sum of all 3. Percent total dural buckling was calculated as the sum of anterior and posterior buckling also divided by the sum of all 3 measurements.

One of the tension cadavers and one of the dural buckling cadavers were excluded from data analysis because of incongruous results secondary to desiccation of the spinal cord, dura, and filum. In one of the included tension cadavers, the PSO and VCR showed extremely variable tension reduction during the $10-\mathrm{g}$ trial; thus, only the 20 - and $40-\mathrm{g}$
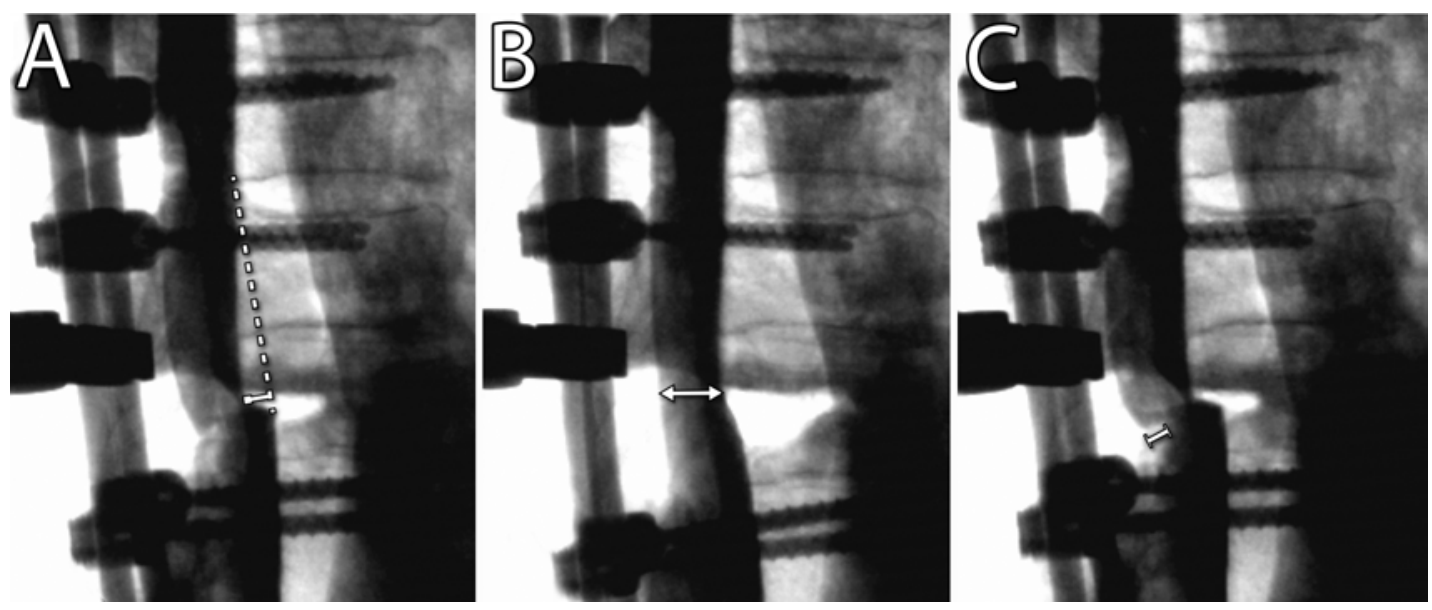

FIG. 2. Lateral radiographs from Experiment 2 demonstrating radiographic measurements. A: Anterior dural buckling: A reference line (dashed white line) is drawn from the most anterior part of the dura rostral and caudal to the osteotomy site. An orthogonal line (solid white line) from this reference line is then drawn to the dura at the osteotomy level. The length of this orthogonal line (solid white line) was defined as anterior buckling. B: Canal width: The narrowest distance of the thecal sac illuminated by contrast at the osteotomy site was measured (double-headed arrow). C: Posterior dural buckling: A reference line was inferred along the posterior dural margin, and an orthogonal distance (solid white line) to the deepest point of posterior indentation was measured. 

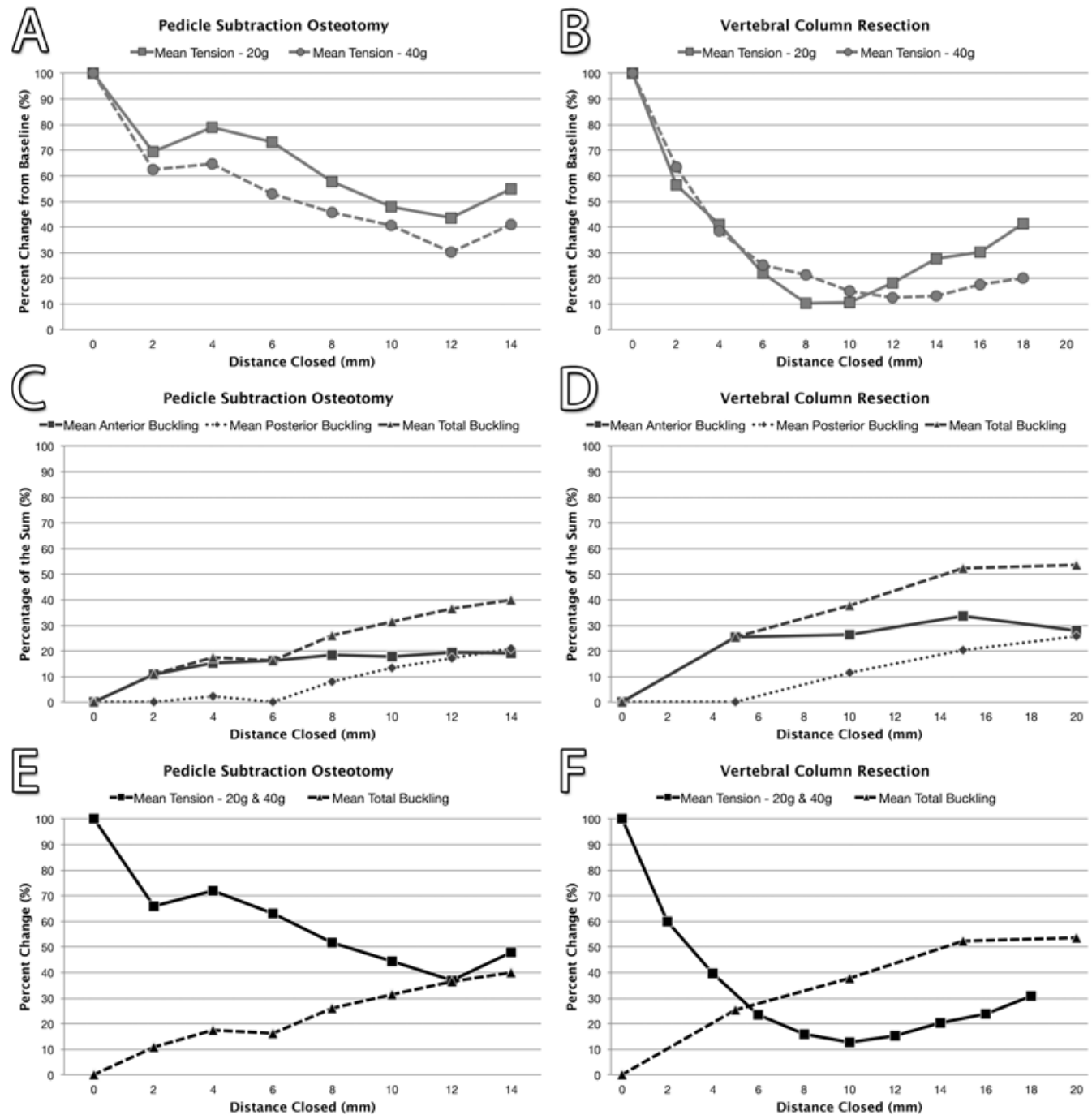

FIG. 3. Graphs depicting the mean tension and dural buckling due to PSOs and VCRs observed in 2 cadavers for each experiment. A: Mean tension reduction due to PSOs in 2 cadavers, each under $20 \mathrm{~g}$ and $40 \mathrm{~g}$ of baseline tension. B: Mean tension reduction due to VCRs in 2 cadavers, each under $20 \mathrm{~g}$ and $40 \mathrm{~g}$ of baseline tension. C: Mean percent anterior buckling, mean percent posterior buckling, and mean percent total buckling due to PSOs in 2 cadavers. D: Mean percent anterior buckling, mean percent posterior buckling, and mean percent total buckling due to VCRs in 2 cadavers. E: Given the close association of the 2 curves depicted in panel $\mathrm{A}$, the mean tension reduction was calculated between the $20 \mathrm{~g}$ and $40 \mathrm{~g}$ trials (4 mean tension-reduction values from 2 cadavers) and plotted against percent total dural buckling from panel C (2 mean values from 2 cadavers). F: Given the close association of the 2 curves depicted in panel B, the mean tension reduction was calculated between the $20 \mathrm{~g}$ and $40 \mathrm{~g}$ trials ( 4 mean tension-reduction values from 2 cadavers) and plotted against percent total dural buckling from panel D ( 2 mean values from 2 cadavers).

baseline data are reported. In this cadaver, pedicle screw fixation was also lost during compression of the SPO, thus the SPO tension data only derive from one cadaver.

\section{Results}

\section{Osteotomy Effects on Spinal Cord Tension}

\section{Smith-Petersen Osteotomy}

In the one cadaver that could be analyzed, the SPO minimized filum tension at $2 \mathrm{~mm}$ of closure (10 g: $-16.1 \%$ ). Tension returned to baseline levels by $6 \mathrm{~mm}$ of compression (Table 1). Given the minimal result, the experiment was not repeated with 20 - or 40 -g baseline tensions.

\section{Pedicle Subtraction Osteotomy}

From the PSO, we saw the greatest change in tension within the initial $2 \mathrm{~mm}$ of closure (mean $20 \mathrm{~g}$ : $-30.6 \%$ [n $=2]$; mean $40 \mathrm{~g}$ : $-37.4 \%$ [ $\mathrm{n}=2] ; 20 \mathrm{~g}$ and $40 \mathrm{~g}$ combined mean: $-34.0 \%[\mathrm{n}=4]$ ) (Table 1, Fig. 3A and E). However, this was not sustained; we observed a relative mean tension increase of $9.6 \%(20 \mathrm{~g} ; \mathrm{n}=2), 2.0 \%(40 \mathrm{~g} ; \mathrm{n}=2)$, and $5.8 \%$ (20- and 40-g combined mean, $\mathrm{n}=4$ ) between 2 and $4 \mathrm{~mm}$ of closure. This increase was common to both curves.

Between 4 and $12 \mathrm{~mm}$, we found linear patterns in every curve. The rates of tension reduction within these segments were $9.61 \% / \mathrm{mm}\left(\mathrm{r}^{2}=0.966\right)$ from the mean $20-\mathrm{g}$ trial, $8.10 \% / \mathrm{mm}\left(\mathrm{r}^{2}=0.983\right)$ from the mean $40-\mathrm{g}$ trial, and 
TABLE 1. Effect of spinal osteotomies on spinal cord tension

\begin{tabular}{|c|c|c|c|c|}
\hline $\begin{array}{l}\text { Osteotomy/Distance } \\
\text { Closed }(\mathrm{mm})\end{array}$ & $\begin{array}{l}\text { Mean \% Change in } \\
\text { Tension from 10-g } \\
\text { Baseline }\end{array}$ & $\begin{array}{c}\text { Mean \% Change in } \\
\text { Tension from 20-g } \\
\text { Baseline }\end{array}$ & $\begin{array}{l}\text { Mean \% Change in } \\
\text { Tension from } 40-g \\
\text { Baseline }\end{array}$ & $\begin{array}{c}\text { Mean \% Change in } \\
\text { Tension from 20-g \& 40-g } \\
\text { Baselines }\end{array}$ \\
\hline SPO & $(n=1)$ & $(n=1)$ & $(n=1)$ & $(n=1)$ \\
\hline 0 & 0.00 & 0.00 & 0.00 & 0.00 \\
\hline 2 & -16.1 & Pedicle failure & Pedicle failure & Pedicle failure \\
\hline 4 & -5.94 & - & - & - \\
\hline 6 & +1.16 & - & - & - \\
\hline PSO & $(n=2)$ & $(n=2)$ & $(n=2)$ & $(n=4)$ \\
\hline 0 & 0.00 & 0.00 & 0.00 & 0.00 \\
\hline 2 & -28.1 & -30.6 & -37.4 & -34.0 \\
\hline 4 & -26.3 & -21.0 & -35.4 & -28.2 \\
\hline 6 & -29.3 & -26.6 & -47.1 & -36.9 \\
\hline 8 & -25.0 & -42.4 & -54.1 & -48.2 \\
\hline 10 & -5.93 & -52.0 & -59.4 & -55.7 \\
\hline 12 & +29.2 & -56.3 & -69.8 & -63.1 \\
\hline 14 & +86.1 & -45.0 & -59.1 & -52.0 \\
\hline VCR & $(n=2)$ & $(n=2)$ & $(n=2)$ & $(n=4)$ \\
\hline 0 & 0.00 & 0.00 & 0.00 & 0.00 \\
\hline 2 & -61.5 & -43.6 & -36.5 & -40.1 \\
\hline 4 & -66.5 & -58.9 & -61.5 & -60.2 \\
\hline 6 & -75.6 & -77.9 & -75.0 & -76.4 \\
\hline 8 & -79.4 & -89.7 & -78.7 & -84.2 \\
\hline 10 & -82.1 & -89.5 & -85.0 & -87.2 \\
\hline 12 & $-65.1(n=1)^{*}$ & -81.7 & -87.5 & -84.6 \\
\hline 14 & $-67.5(n=1)^{*}$ & -72.4 & -86.9 & -79.7 \\
\hline 16 & $-74.6(n=1)^{*}$ & -69.8 & -82.4 & -76.1 \\
\hline 18 & $\mathrm{NP}+$ & -58.8 & -79.7 & -69.3 \\
\hline
\end{tabular}

$8.86 \% / \mathrm{mm}\left(\mathrm{r}^{2}=0.993\right)$ from the mean of the 2 trials combined. At $12 \mathrm{~mm}$ of closure, the PSO minimized mean tension in every curve (mean $20 \mathrm{~g}$ : $-56.3 \%$ [ $=2$ ]; mean 40 g: $-69.8 \%[n=2] ; 20$ - and 40-g combined mean: $-63.1 \%$ $[\mathrm{n}=4]$ ) (Table 1, Fig. 3A and E). Yet between 12 and 14 $\mathrm{mm}$ of closure, we saw a relative mean tension increase of $11.3 \%(20 \mathrm{~g} ; \mathrm{n}=2), 10.7 \%(40 \mathrm{~g} ; \mathrm{n}=2)$, and $11.1 \%$ (20- and 40 -g combined mean; $n=4)$, which disrupted the preceding linear relationship. Overall, the mean 40-g baseline trial demonstrated greater tension reduction than the mean 20-g baseline trial.

\section{Vertebral Column Resection}

The VCR curves exhibited rapid initial tension reductions and slowly reached plateaus. Again, we saw the greatest change in tension reduction within the initial $2 \mathrm{~mm}$ of closure (mean $20 \mathrm{~g}:-43.6 \%$ [n $=2$ ]; mean $40 \mathrm{~g}:-36.5 \%$ [n $=2]$; 20- and 40-g combined mean: $-40.1 \%[\mathrm{n}=4]$ ) (Table 1, Fig. 3B and F). Given the complex curve, we isolated the $0-6-\mathrm{mm}$ segment for linear regression. This portion of tension reduction was comparable between all curves (Fig. $3 \mathrm{~B}$ and $\mathrm{F})$. The rates of tension reduction were $24.9 \% / \mathrm{mm}$ $\left(\mathrm{r}^{2}=0.939\right)$ for the mean 20 -g baseline, $25.0 \% / \mathrm{mm}\left(\mathrm{r}^{2}=\right.$ $0.959)$ for the mean $40-\mathrm{g}$ baseline, and $24.9 \% / \mathrm{mm}\left(\mathrm{r}^{2}=\right.$ 0.953 ) for the mean of the 2 trials within this span.

Each curve achieved minimal residual tension with a different amount of closure. The mean 20-g trial decreased by $89.7 \%(\mathrm{n}=2)$ at $8 \mathrm{~mm}$. The mean $40 \mathrm{-g}$ trial decreased by $87.5 \%(\mathrm{n}=2)$ at $12 \mathrm{~mm}$. The curve depicting the average of these data sets decreased by $87.2 \%(n=4)$ at $10 \mathrm{~mm}$.

The mean 20- and 40-g curves began to diverge at the distance between their respective minima and $18 \mathrm{~mm}$ (Fig. 3B). Between 8 and $18 \mathrm{~mm}$ of closure, the mean $20 \mathrm{-g}$ trial demonstrated a relative increase in tension $(30.9 \%$; $=2$ ), while the mean 40-g trial began to plateau, and only showed a $7.8 \%(n=2)$ relative tension increase between 12 and $18 \mathrm{~mm}$. The mean of these curves indicated a net relative increase in tension of $17.9 \%(n=4)$.

\section{Osteotomy Effects on Dural Buckling}

Smith-Petersen Osteotomy

The SPO did not demonstrate dural buckling at any distance of closure (Table 2). 
TABLE 2. Effect of spinal osteotomies on dural buckling*

\begin{tabular}{|c|c|c|c|c|}
\hline $\begin{array}{l}\text { Osteotomy/Distance } \\
\text { Closed }(\mathrm{mm})\end{array}$ & $\begin{array}{l}\text { Mean \% Anterior Buckling } \\
\quad \& \text { Absolute Change }\end{array}$ & $\begin{array}{l}\text { Mean \% Canal Width } \\
\& \text { Absolute Change }\end{array}$ & $\begin{array}{l}\text { Mean \% Posterior Buckling } \\
\quad \& \text { Absolute Change }\end{array}$ & $\begin{array}{c}\text { Mean } \% \text { Change in } \\
\text { Total Dural Buckling (\%) }\end{array}$ \\
\hline SPO & $(n=1)$ & $(n=1)$ & $(n=1)$ & $(n=1)$ \\
\hline 0 & $0.00(0.00)$ & $100(10.4)$ & $0.00(0.00)$ & 0.00 \\
\hline 2 & $0.00(0.00)$ & $100(11.0)$ & $0.00(0.00)$ & 0.00 \\
\hline 4 & $0.00(0.00)$ & $100(10.6)$ & $0.00(0.00)$ & 0.00 \\
\hline 6 & $0.00(0.00)$ & $100(10.9)$ & $0.00(0.00)$ & 0.00 \\
\hline PSO & $(n=2)$ & $(n=2)$ & $(n=2)$ & $(n=2)$ \\
\hline 0 & $0.00(0.00)$ & $100(10.6)$ & $0.00(0.00)$ & 0.00 \\
\hline 2 & $10.9(1.33)$ & $89.1(10.9)$ & $0.00(0.00)$ & 10.9 \\
\hline 4 & $15.2(1.98)$ & $82.5(10.7)$ & $2.32(0.30)$ & 17.5 \\
\hline 6 & $16.3(2.20)$ & $83.7(11.3)$ & $0.00(0.00)$ & 16.3 \\
\hline 8 & $18.3(2.69)$ & $73.8(10.8)$ & $7.90(1.16)$ & 26.2 \\
\hline 10 & $17.9(2.72)$ & $68.6(10.4)$ & $13.5(2.05)$ & 31.4 \\
\hline 12 & $19.5(2.91)$ & $63.3(9.47)$ & $17.2(2.57)$ & 36.7 \\
\hline 14 & $19.0(2.93)$ & $60.1(9.28)$ & $20.9(3.22)$ & 39.9 \\
\hline VCR & $(n=2)$ & $(n=2)$ & $(n=2)$ & $(n=2)$ \\
\hline 0 & $0.00(0.00)$ & $100(10.2)$ & $0.00(0.00)$ & 0.00 \\
\hline 5 & $25.4(3.21)$ & $74.6(9.44)$ & $0.00(0.00)$ & 25.4 \\
\hline 10 & $26.5(4.44)$ & $62.0(10.4)$ & $11.5(1.92)$ & 38.0 \\
\hline 15 & $33.5(6.17)$ & $46.1(8.48)$ & $20.4(3.74)$ & 53.9 \\
\hline 20 & $28.0(4.67)$ & $46.3(7.73)$ & $25.7(4.28)$ & 53.7 \\
\hline
\end{tabular}

* Data given as $\%(\mathrm{~mm})$ unless otherwise indicated.

\section{Pedicle Subtraction Osteotomy}

PSO dural buckling data are presented in Fig. $3 \mathrm{C}$ and Table 2. PSO mean total dural buckling began at $2 \mathrm{~mm}$ of closure and steadily increased linearly. The overall rate of narrowing was $5.47 \% / \mathrm{mm}\left(r^{2}=0.967\right)$. We observed maximal mean total buckling $(39.9 \% ; \mathrm{n}=2)$ at $14 \mathrm{~mm}$ of shortening.

Mean total buckling was attributable to both anterior and posterior components of dural buckling. Mean anterior dural buckling rose at a rate of $7.61 \% / \mathrm{mm}\left(\mathrm{r}^{2}=0.942\right)$ to $15.2 \%(n=2)$ over the first $4 \mathrm{~mm}$. Thereafter, mean anterior buckling plateaued, only achieving a maximum of $19.5 \%(n=2)$. Mean anterior buckling made the largest contribution to mean total buckling within the first $4 \mathrm{~mm}$ of closure. In contrast, mean posterior buckling made the largest contribution after $8 \mathrm{~mm}$ (Fig. 3C).

Mean posterior dural buckling did not begin until $8 \mathrm{~mm}$ of shortening. It increased linearly at a rate of $5.10 \% / \mathrm{mm}$ $\left(r^{2}=0.969\right)$ to a maximal level of $20.9 \%(n=2)$ by $14 \mathrm{~mm}$ of closure.

\section{Vertebral Column Resection}

VCR dural buckling data are presented in Fig. 3D and Table 2. Mean VCR total dural buckling increased linearly between 0 and $15 \mathrm{~mm}$ of closure. The rate of mean total buckling in this segment was $16.9 \% / \mathrm{mm}\left(\mathrm{r}^{2}=0.971\right)$. Mean total buckling plateaued at a maximal value of $53.9 \%(\mathrm{n}=$ 2) with $15 \mathrm{~mm}$ of shortening.

Again, mean total buckling was attributable to both anterior and posterior components of dural buckling. Mean anterior buckling rose to $25.4 \%(\mathrm{n}=2)$ over the first 5 $\mathrm{mm}$. It subsequently plateaued and only achieved a maximum of $33.5 \%(\mathrm{n}=2)$ within the next $10 \mathrm{~mm}$ of reduction. Linear regression was not performed, since the most substantial increase occurred between 2 adjacent data points. Mean anterior buckling made the largest contribution to mean total buckling within the first $5 \mathrm{~mm}$ of closure, while mean posterior buckling made the largest contribution after $5 \mathrm{~mm}$.

Mean posterior buckling began after $5 \mathrm{~mm}$ and rose in a linear fashion to reach a maximum of $25.7 \%(\mathrm{n}=2)$ at 20 $\mathrm{mm}$ of shortening. The rate of increase was $8.58 \% / \mathrm{mm}\left(\mathrm{r}^{2}\right.$ $=0.975)$ within this distance.

\section{Discussion}

In 1995, Kokubun ${ }^{18}$ described the technique of spinal shortening and later applied the technique in lieu of traditional detethering to a series of 8 patients with lipomyelomeningocele. In 2006, Grande et al. ${ }^{8}$ conducted a very similar cadaveric study to assess the effects of a VCR on spinal cord, nerve root, and filum tension. They reported that a reduction of vertebral column length of $15-25 \mathrm{~mm}$ achieved the same effect as a standard detethering procedure that required release of more than $90 \%$ of neural elements. Absent from both of these studies, however, was an assessment of the effect of spinal osteotomy closure on dural buckling.

In the current report, we have demonstrated that spinal osteotomies in the lower thoracic spine have a progressive ability to reduce spinal cord tension in a human cadav- 
eric model. With a maximal tension reduction of $16.1 \%$, the SPO seems to provide very little in tension relief and, therefore, does not seem to be the best option for the treatment of recurrent tethered cord syndrome. The tensionrelieving effect of the SPO may be limited by the height of the anterior disc space and the presence of osteophytic changes. ${ }^{2}$

In contrast, the mean spinal cord tension fell substantially with both the PSO and VCR, in concordance with our expectations. Furthermore, when regression was performed on the identifiable linear segments, the VCR showed a rate of tension reduction nearly twice that of the PSO. There was an unexpected relative increase in tension between 2 and $4 \mathrm{~mm}$ of PSO closure. This was unique to the PSO and may have been due to experimental technique, as distraction of the PSO was necessary to achieve the baseline distance that was measured before surgery. This distraction may have added additional tension on the filum that overestimated the initial tension reduction and underestimated the subsequent 2-4-mm tension reduction relative to a higher than expected baseline.

At the end of the tension curves, both the PSO and VCR also showed a relative increase. This terminal increase in reduction was smallest for the 40-g VCR. This was a rather counterintuitive finding, since one would expect a higher baseline tension to show a greater tension increase. This could potentially be confounded by a change in tissue elasticity due to fixation or secondary to dural buckling, which was evaluated on separate cadavers.

As expected, canal narrowing due to dural buckling increased in both the PSO and VCR groups but, overall, increased at a faster rate and reached a higher maximum with the VCR than the PSO (Table 2, Fig. 3C and D). Overall, anterior and posterior buckling plateaued at the same level for each osteotomy, but at different distances of closure. The anterior component of dural buckling preceded the posterior component in both the PSOs and the VCRs. Since this observation was not osteotomy-specific, it could be related to the degree of kyphosis, as this seemed to vary between specimens. The rate of posterior buckling was also lower for both osteotomies. Thus, not only did posterior buckling occur later, but it also occurred more slowly, which would make the change less obvious. It may also be that the removal of posterior elements ${ }^{3}$ or the thickness of the dura itself ${ }^{9}$ allowed for the release of any dural buckling. Any of these factors could explain the observed differences between our study and that of Grande et al. ${ }^{8}$

While the myelograms obtained during this study do not allow visualization of the spinal cord, previous research has demonstrated that the diameter of the human spinal cord at T-10 ranges from about $5 \mathrm{~mm}$ to about 9.5 $\mathrm{mm}$ in the transverse plane and from about $4 \mathrm{~mm}$ to about $8.5 \mathrm{~mm}$ in the sagittal plane..$^{17}$ The minimal canal width measured in this study ( $7.73 \mathrm{~mm}$ after closure of the VCR) is within a range that may leave insufficient room for the spinal cord and could result in damage to the spinal cord itself. Although saline was injected into the thecal sac to simulate CSF in our model, such an approximation fails to account for the dynamic CSF pulsations seen in vivo. These pulsations may affect dural buckling parameters and physiological conditions; therefore, specific conclu- sions about dural buckling may be limited to the basic generalities that dural buckling can increase with more aggressive osteotomies and that anterior buckling typically proceeds posterior buckling.

The PSO tension and dural buckling curves came closest to intersecting at $12 \mathrm{~mm}$, but they never crossed (Fig. $3 \mathrm{E})$. Overall, mean tension was reduced at a faster rate than dural buckling increased (Fig. 3E). However, this relationship became less favorable at $14 \mathrm{~mm}$, when tension increased (Fig. 3E). Thus, we conclude that the region bounded by the 2 curves between 6 and $12 \mathrm{~mm}$ of compression may represent the most favorable ratio of tension reduction and dural buckling.

The mean tension and dural buckling curves for the VCR intersected just before $6 \mathrm{~mm}$ of closure (Fig. 3F). The VCR afforded a better ratio of tension reduction to dural buckling than the PSO between 2 and $10 \mathrm{~mm}$ of closure, even despite a faster rate of dural buckling. This ratio became less favorable between 12 to $18 \mathrm{~mm}$, but the benefit between the 2 curves was still greater for the VCR than the PSO. Thus, the region bounded by the 2 curves between 12 and $16 \mathrm{~mm}$ may suggest that the VCR is preferable to the PSO in patients requiring a greater degree of shortening.

Since spinal cord tension was minimized between 12 and $16 \mathrm{~mm}$ of closure using both a PSO and VCR with minor increases in dural buckling, we see this as the optimal safe range of closure if performing these procedures for recurrent tethered cord syndromes. Our findings conflict with those of the cadaveric study reported by Grande et al., ${ }^{8}$ because their cohort required approximately $20 \mathrm{~mm}$ of closure to achieve an $80 \%$ reduction in tension. However, they only used a spinal cord/filum tension of approximately $5 \mathrm{~g}$. Our methodology differed in that we simulated a tethered cord by varying the initial tensions among 10 $\mathrm{g}, 20 \mathrm{~g}$, and $40 \mathrm{~g}$. An adjustment of either one of our experiments to the same baseline tension might yield similar results. It is unclear how our dural buckling results would compare because Grande et al. did not report this parameter. However, our data highlight the need for caution and intraoperative monitoring if patients undergo spinal shortening beyond $16 \mathrm{~mm}$.

Data collected from cadaveric models may be difficult to extrapolate to in vivo conditions because of properties such as biomechanical attributes, flexibility, and fixation. Furthermore, the specimens that were analyzed did not have spinal cord tethering and were likely of different demographics than most of the patients in the tetheredcord population. Thus, such patients' spines and neural elements may be different than the cadaveric specimens used. Another limitation of this study is the exclusion of data. We felt it was justified to exclude the 2 cadavers that provided incongruous results because these cadavers were confounded by desiccation. Desiccation may have affected our measurements by altering the elasticity/tension in the spinal cord and the compression/buckling of the dura. This could explain why these cadavers provided such paradoxical results. Additional factors not mentioned herein that vary from individual to individual may also explain why these 2 cadavers consistently provided outlier results. While the exact numbers and parameters reported herein may not be clinically translatable presently, basic general- 
izations gained from our analysis could serve as a basis for future in vivo research.

\section{Conclusions}

We have demonstrated that significant reduction in spinal cord tension can be achieved with both PSOs and VCRs. We have also demonstrated that significant reduction in vertebral column height also causes dural buckling that may lead to neural compression. Approximately 12-16 mm of closure of either a PSO or VCR seems to mitigate the risks of dural buckling while allowing a significant reduction in spinal cord tension. However, future study is warranted on live animal models and in clinical series of human subjects undergoing this procedure to further support these conclusions.

\section{References}

1. Al-Holou WN, Muraszko KM, Garton HJ, Buchman SR, Maher CO: The outcome of tethered cord release in secondary and multiple repeat tethered cord syndrome. J Neurosurg Pediatr 4:28-36, 2009

2. Al-Rawahi M, Luo J, Pollintine P, Dolan P, Adams MA: Mechanical function of vertebral body osteophytes, as revealed by experiments on cadaveric spines. Spine (Phila Pa 1976) 36:770-777, 2011

3. Alemdaroğlu KB, Atlihan D, Cimen O, Kilinç CY, Iltar S: Morphometric effects of acute shortening of the spine: the kinking and the sliding of the cord, response of the spinal nerves. Eur Spine J 16:1451-1457, 2007

4. Bowman RM, McLone DG, Grant JA, Tomita T, Ito JA: Spina bifida outcome: a 25 -year prospective. Pediatr Neurosurg 34:114-120, 2001

5. Bowman RM, Mohan A, Ito J, Seibly JM, McLone DG: Tethered cord release: a long-term study in 114 patients. J Neurosurg Pediatr 3:181-187, 2009

6. Cochrane DD: Cord untethering for lipomyelomeningocele: expectation after surgery. Neurosurg Focus 23(2):E9, 2007

7. Filler AG, Britton JA, Uttley D, Marsh HT: Adult postrepair myelomeningocoele and tethered cord syndrome: good surgical outcome after abrupt neurological decline. Br J Neurosurg 9:659-666, 1995

8. Grande AW, Maher PC, Morgan CJ, Choutka O, Ling BC, Raderstorf TC, et al: Vertebral column subtraction osteotomy for recurrent tethered cord syndrome in adults: a cadaveric study. J Neurosurg Spine 4:478-484, 2006

9. Hong JY, Suh SW, Park SY, Modi HN, Rhyu IJ, Kwon S, et al: Analysis of dural sac thickness in human spine-cadaver study with confocal infrared laser microscope. Spine J 11:1121-1127, 2011

10. Hsieh PC, Ondra SL, Grande AW, O’Shaughnessy BA, Bierbrauer K, Crone KR, et al: Posterior vertebral column subtraction osteotomy: a novel surgical approach for the treatment of multiple recurrences of tethered cord syndrome. J Neurosurg Spine 10:278-286, 2009

11. Hsieh PC, Stapleton CJ, Moldavskiy P, Koski TR, Ondra SL, Gokaslan ZL, et al: Posterior vertebral column subtraction osteotomy for the treatment of tethered cord syndrome: review of the literature and clinical outcomes of all cases reported to date. Neurosurg Focus 29(1):E6, 2010

12. Hüttmann S, Krauss J, Collmann H, Sörensen N, Roosen K: Surgical management of tethered spinal cord in adults: report of 54 cases. J Neurosurg 95 (2 Suppl):173-178, 2001

13. Inoue HK, Kobayashi S, Ohbayashi K, Kohga H, Nakamura $\mathrm{M}$ : Treatment and prevention of tethered and retethered spinal cord using a Gore-Tex surgical membrane. J Neurosurg 80:689-693, 1994
14. Kanev PM, Lemire RJ, Loeser JD, Berger MS: Management and long-term follow-up review of children with lipomyelomeningocele, 1952-1987. J Neurosurg 73:48-52, 1990

15. Kanno H, Aizawa T, Ozawa H, Hoshikawa T, Itoi E, Kokubun S: Spine-shortening vertebral osteotomy in a patient with tethered cord syndrome and a vertebral fracture. Case report. J Neurosurg Spine 9:62-66, 2008

16. Kawahara N, Tomita K, Kobayashi T, Abdel-Wanis ME, Murakami $\mathrm{H}$, Akamaru T: Influence of acute shortening on the spinal cord: an experimental study. Spine (Phila Pa 1976) 30:613-620, 2005

17. Ko HY, Park JH, Shin YB, Baek SY: Gross quantitative measurements of spinal cord segments in human. Spinal Cord 42:35-40, 2004

18. Kokubun S: [Shortening spinal osteotomy for TCS in adults.] Spine Spinal Cord 8 (Suppl 12):5, 1995 (Jpn)

19. Kokubun S, Ozawa H, Aizawa T, Ly NM, Tanaka Y: Spineshortening osteotomy for patients with tethered cord syndrome caused by lipomyelomeningocele. J Neurosurg Spine 15:21-27, 2011

20. Koyanagi I, Iwasaki Y, Hida K, Abe H, Isu T, Akino M: Surgical treatment supposed natural history of the tethered cord with occult spinal dysraphism. Childs Nerv Syst 13:268274, 1997

21. Lapsiwala SB, Iskandar BJ: The tethered cord syndrome in adults with spina bifida occulta. Neurol Res 26:735-740, 2004

22. Macejko AM, Cheng EY, Yerkes EB, Meyer T, Bowman RM, Kaplan WE: Clinical urological outcomes following primary tethered cord release in children younger than 3 years. J Urol 178:1738-1743, 2007

23. Maher CO, Goumnerova L, Madsen JR, Proctor M, Scott RM: Outcome following multiple repeated spinal cord untethering operations. J Neurosurg 106 (6 Suppl):434-438, 2007

24. Miyakoshi N, Abe E, Suzuki T, Kido T, Chiba M, Shimada Y: Spine-shortening vertebral osteotomy for tethered cord syndrome: report of three cases. Spine (Phila Pa 1976) 34:E823-E825, 2009

25. Tanabe F, Yone K, Kawabata N, Sakakima H, Matsuda F, Ishidou Y, et al: Accumulation of p62 in degenerated spinal cord under chronic mechanical compression: functional analysis of p62 and autophagy in hypoxic neuronal cells. Autophagy 7:1462-1471, 2011

\section{Author Contributions}

Conception and design: Hwang, Safain, Burke, Riesenburger. Acquisition of data: all authors. Analysis and interpretation of data: Hwang, Safain, Burke, Riesenburger. Drafting the article: Hwang, Safain, Burke, Riesenburger. Critically revising the article: all authors. Reviewed submitted version of manuscript: all authors. Approved the final version of the manuscript on behalf of all authors: Hwang. Statistical analysis: Hwang, Safain, Burke, Riesenburger. Administrative/technical/material support: Hwang, Riesenburger. Study supervision: Hwang, Riesenburger.

\section{Supplemental Information}

\section{Previous Presentation}

Portions of this work were presented in abstract form at the New England Neurosurgical Society Meeting, Brewster, MA, June 27, 2014.

\section{Correspondence}

Steven W. Hwang, Department of Neurosurgery, Tufts Medical Center, 800 Washington St. \#178, Proger 7, Boston, MA 02111. email: shwang@tuftsmedicalcenter.org. 